\title{
An Evaluation of Continuity Clinic Redesign
}

Mark L. Wieland, MD, MPH' , Andrew J. Halvorsen, $M S^{2}$, Rajeev Chaudhry, MBBS, MPH', Darcy A. Reed, MD, MPH ${ }^{7}$, Furman S. McDonald, MD, $\mathrm{MPH}^{2,3}$, and Kris G. Thomas, $\mathrm{MD}^{7}$

'Division of Primary Care Internal Medicine, Mayo Clinic, Rochester, MN, USA; ${ }^{2}$ nternal Medicine Residency Office of Educational Innovations, Mayo Clinic, Rochester, MN, USA; ${ }^{3}$ Divisions of General and Hospital Internal Medicine, Mayo Clinic, Rochester, MN, USA.

$J$ Gen Intern Med 28(12):1557

DOI: $10.1007 / \mathrm{s} 11606-013-2613-\mathrm{z}$

( ) Society of General Internal Medicine 2013

$\mathrm{T}$ he Authors' Reply—Dr. Buckhold and colleagues report their experience with residency continuity clinics following the transition of their program to a $50 / 50$ outpatient-inpatient model. The educational and clinical outcomes that they assessed showed similar results to our findings, adding to the generalizability of our study. We agree with their call for future research to compare the impact of different block models on patient relevant outcomes. Likewise, there is further need to explore ways to preserve or improve continuity of care within the 50/50 model.

Corresponding Author: Mark L. Wieland, MD, MPH; Division of Primary Care Internal Medicine, Mayo Clinic, 200 First Street SW, Rochester, MN 55904, USA (e-mail: wieland.mark@mayo.edu). 